\title{
Horizontal tuning for faces originates in high-level Fusiform Face Area
}

Citation for published version (APA):

Goffaux, V., Duecker, F., Hausfeld, L., Schiltz, C., \& Goebel, R. (2016). Horizontal tuning for faces originates in high-level Fusiform Face Area. Neuropsychologia, 81, 1-11.

https://doi.org/10.1016/j.neuropsychologia.2015.12.004

Document status and date:

Published: 29/01/2016

DOI:

10.1016/j.neuropsychologia.2015.12.004

Document Version:

Publisher's PDF, also known as Version of record

Document license:

Taverne

Please check the document version of this publication:

- A submitted manuscript is the version of the article upon submission and before peer-review. There can be important differences between the submitted version and the official published version of record.

People interested in the research are advised to contact the author for the final version of the publication, or visit the DOI to the publisher's website.

- The final author version and the galley proof are versions of the publication after peer review.

- The final published version features the final layout of the paper including the volume, issue and page numbers.

Link to publication

\footnotetext{
General rights rights.

- You may freely distribute the URL identifying the publication in the public portal. please follow below link for the End User Agreement:

www.umlib.nl/taverne-license

Take down policy

If you believe that this document breaches copyright please contact us at:

repository@maastrichtuniversity.nl

providing details and we will investigate your claim.
}

Copyright and moral rights for the publications made accessible in the public portal are retained by the authors and/or other copyright owners and it is a condition of accessing publications that users recognise and abide by the legal requirements associated with these

- Users may download and print one copy of any publication from the public portal for the purpose of private study or research.

- You may not further distribute the material or use it for any profit-making activity or commercial gain

If the publication is distributed under the terms of Article $25 \mathrm{fa}$ of the Dutch Copyright Act, indicated by the "Taverne" license above, 


\title{
Horizontal tuning for faces originates in high-level Fusiform Face Area
}

\author{
Valerie Goffaux ${ }^{\mathrm{a}, \mathrm{b}, \mathrm{c}, *}$, Felix Duecker ${ }^{\mathrm{c}, \mathrm{d}}$, Lars Hausfeld ${ }^{\mathrm{c}, \mathrm{d}}$, Christine Schiltz ${ }^{\mathrm{e}}$, \\ Rainer Goebel ${ }^{\mathrm{c}, \mathrm{d}}$ \\ a Research Institute for Psychological Sciences, Université Catholique de Louvain, Belgium \\ ${ }^{\mathrm{b}}$ Institute of Neuroscience, Université Catholique de Louvain, Belgium \\ ${ }^{\mathrm{c}}$ Department of Cognitive Neuroscience, Faculty of Psychology and Neuroscience, Maastricht University, The Netherlands \\ ${ }^{\mathrm{d}}$ Maastricht Brain Imaging Center, Maastricht University, The Netherlands \\ e Education, Culture, Cognition and Society (ECCS) Unit, University of Luxembourg, Walferdange, Luxembourg
}

\section{A R T I C L E I N F O}

Article history:

Received 18 August 2015

Received in revised form

23 November 2015

Accepted 6 December 2015

Available online 9 December 2015

Keywords:

Face perception

FFA

OFA

Horizontal

Inversion effect

MVPA

V1

\begin{abstract}
A B S T R A C T
Recent work indicates that the specialization of face visual perception relies on the privileged processing of horizontal angles of facial information. This suggests that stimulus properties assumed to be fully resolved in primary visual cortex (V1; e.g., orientation) in fact determine human vision until high-level stages of processing. To address this hypothesis, the present fMRI study explored the orientation sensitivity of V1 and high-level face-specialized ventral regions such as the Occipital Face Area (OFA) and Fusiform Face Area (FFA) to different angles of face information.

Participants viewed face images filtered to retain information at horizontal, vertical or oblique angles. Filtered images were viewed upright, inverted and (phase-)scrambled. FFA responded most strongly to the horizontal range of upright face information; its activation pattern reliably separated horizontal from oblique ranges, but only when faces were upright. Moreover, activation patterns induced in the right FFA and the OFA by upright and inverted faces could only be separated based on horizontal information. This indicates that the specialized processing of upright face information in the OFA and FFA essentially relies on the encoding of horizontal facial cues.

This pattern was not passively inherited from V1, which was found to respond less strongly to horizontal than other orientations likely due to adaptive whitening. Moreover, we found that orientation decoding accuracy in V1 was impaired for stimuli containing no meaningful shape.

By showing that primary coding in V1 is influenced by high-order stimulus structure and that highlevel processing is tuned to selective ranges of primary information, the present work suggests that primary and high-level levels of the visual system interact in order to modulate the processing of certain ranges of primary information depending on their relevance with respect to the stimulus and task at hand.
\end{abstract}

(c) 2015 Elsevier Ltd. All rights reserved.

\section{Introduction}

Before a face can be recognized, the visual activity induced by its projection on the retina activates a hierarchy of cortical regions located in the ventral occipitotemporal cortex of the primate brain (Felleman and Van Essen, 1991; Grill-Spector and Weiner, 2014). In the most posterior visual region, coined primary visual cortex (V1), neurons have very small receptive fields $(\mathrm{RF})$ and are selective to primary properties of the stimulus. Primary properties mainly refer to the orientation and spatial frequency (SF; Fig.1a) of the local edges constituting the stimulus (De Valois and De Valois,

\footnotetext{
* Corresponding author at: Faculty of Psychology and Educational Sciences, Research Institute for Psychological Science (IPSY), Université Catholique de Louvain, Place Cardinal Mercier 10 box L3.05.01, 1348 Louvain-la-Neuve, Belgium.

E-mail address: valerie.goffaux@uclouvain.be (V. Goffaux).
}

1988; Hawken and Parker, 1987; Hubel and Wiesel, 1968). As the visual information reaches the more anterior and higher-level visual regions, RF size increases and neurons are selective to increasingly complex visual features of the stimulus (Rust and Dicarlo, 2010). At higher hierarchical levels, visual regions are selective to specific stimulus categories (faces, scenes, bodies, etc; Epstein and Kanwisher, 1998; Kanwisher and Yovel, 2006; Rossion et al., 2003; Schwarzlose et al., 2005). Among these, several regions have been shown to respond preferentially to faces. For example, the Occipital Face Area (OFA) located in the inferior occipital gyrus is thought to encode the local cues composing the face such as its features (e.g., eyes, brows, nose, etc; Goffaux et al., 2013; Haxby et al., 2000; Henriksson et al., 2015). More anterior lies the Fusiform Face Area, (FFA; Grill-Spector and Weiner, 2014; Kanwisher et al., 1997; Sergent et al., 1992). FFA is thought to represent facial identity via both the local and interactive encoding 

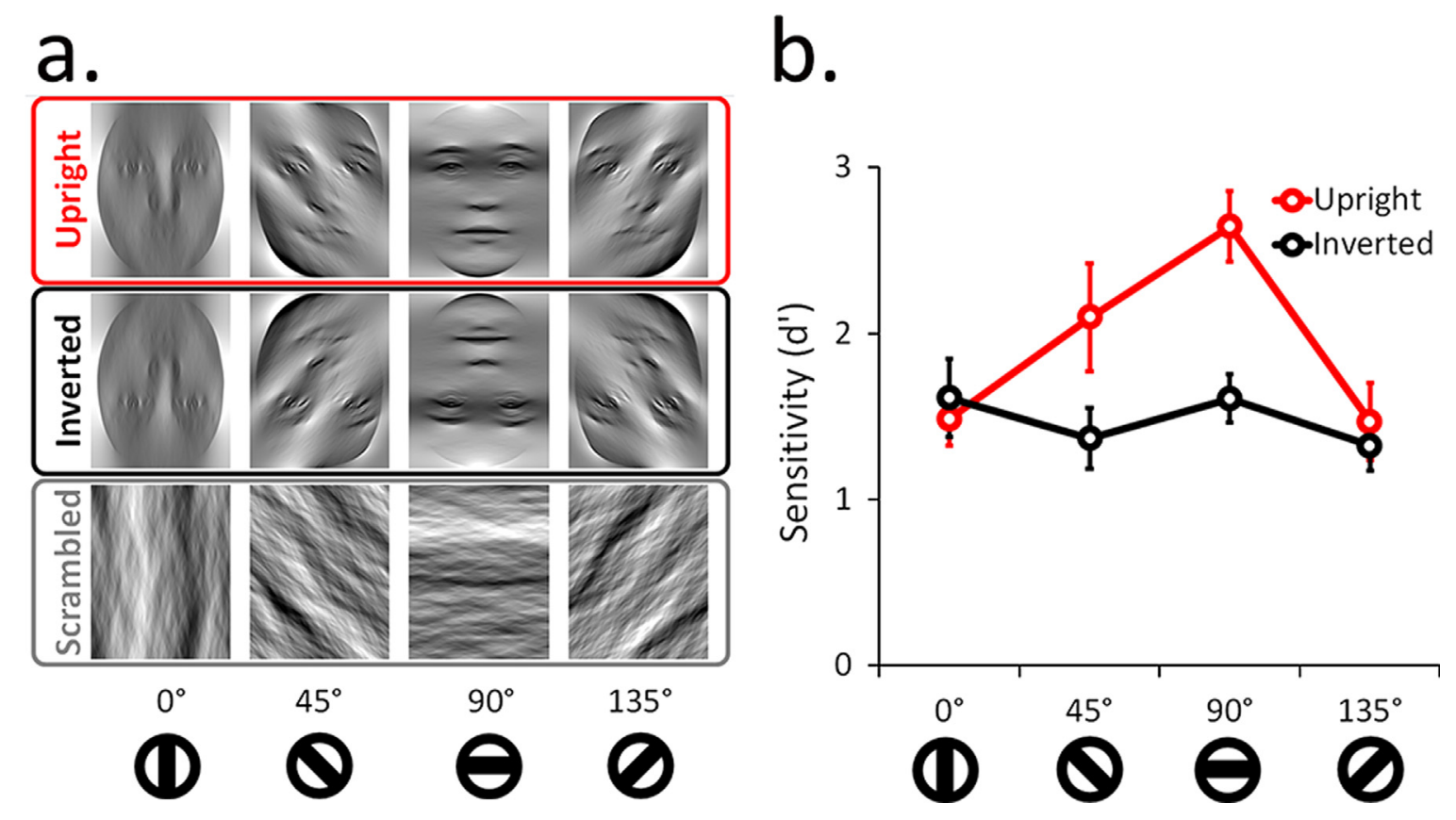

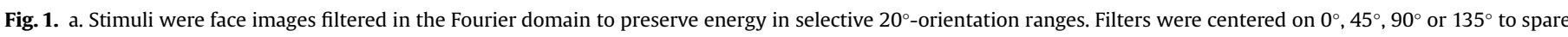

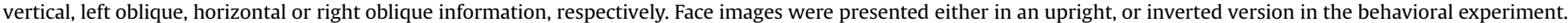

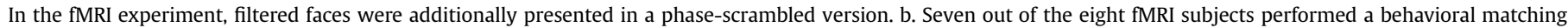

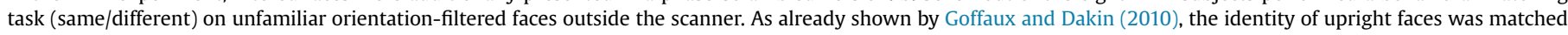

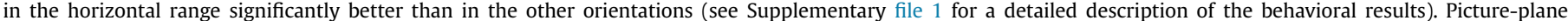

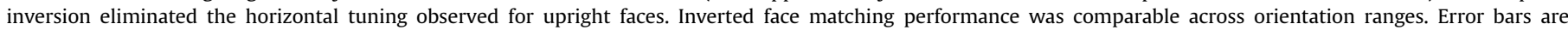
normalized standard errors (Loftus and Masson, 1994).

of facial features (Andrews et al., 2010; Goffaux et al., 2013; Harris and Aguirre, 2010; James et al., 2013; Schiltz and Rossion, 2006; Yovel and Kanwisher, 2004). Even though the FFA is one of the most studied high-level regions in the human visual system, the nature of the visual information that is relayed by lower-level cortical stages to FFA when processing faces remains elusive (Op de Beeck et al., 2008; Rust and Dicarlo, 2010).

The feedforward model of vision (Delorme and Thorpe, 2003; Riesenhuber and Poggio, 1999; Serre et al., 2007) proposes that the complex RF properties in high-level regions like FFA results from the progressive pooling of the primary information encoded in $\mathrm{V} 1$ as the visual signal propagates uni-directionally from low (i.e., posteriorly located) to high (i.e., and more anterior) stages of visual processing (Kobatake and Tanaka, 1994; Op De Beeck and Vogels, 2000; Rust and Dicarlo, 2010). However, recent work showed that the processing of face identity is highly sensitive to primary aspects of the face stimulus like e.g., orientation. This suggests that primary aspects of the stimulus determine visual processing until its high-level stages. The orientation sensitivity of face perception was first put forward by Dakin and Watt, 2009. They filtered face images to retain energy within a narrow band of orientation centered on horizontal to vertical angle. They found that the function relating recognition performance to orientation approximated a Gaussian peaking in the horizontal range and reaching its minimum in the vertical range (Fig. 1). One may argue that this horizontal tuning of face identity perception reflects the fact that face images contain more energy in the horizontal than in other orientation ranges (Keil, 2009). However, Goffaux and Dakin (2010), see also Jacques et al. (2014) and Pachai et al. (2013) showed that the horizontal advantage for the processing of face identity is attenuated or even eliminated when faces are inverted (i.e., turned upside-down). Since the spectral properties (namely, the distribution of energy across orientation and SF) of an image and its inverted version are largely identical, inversion-related declines in performance are generally taken as reflecting the disruption of high-level visual mechanisms rather than imagedriven sampling biases. Moreover, because inversion disrupts the processing of faces more than of other visual categories, the face inversion effect (FIE) is thought to mark the recruitment of visual mechanisms selectively devoted to the processing of upright faces (Farah et al., 1995; McKone et al., 2007; Rhodes et al., 1993; Yin, 1969). For these reasons, it seems likely that the horizontal tuning of face perception reflects face-specialized biases at high-level stages of visual processing. These findings further indicate that primary properties of the stimulus must be taken into account in order to better understand the functional organization of highlevel visual perception (e.g., Andrews et al., 2010; Goffaux, 2009; Goffaux et al., 2011a; Näsänen, 1999).

The present fMRI study addresses the cortical underpinnings of the horizontal tuning of face processing. Are face-selective regions like OFA and FFA tuned to horizontal information? If this is the case, are they horizontally-tuned only when processing upright faces, in agreement with behavioral findings, or are they generally biased towards any class of horizontally-structured stimuli (e.g., inverted faces)? Is OFA, provided its posterior location in the visual stream of processing, more orientation-tuned than the anterior FFA? Is the encoding of horizontal information also privileged in V1 especially when viewing upright faces, possibly as a result of recurrent interactions with high-level face-specialized cortical regions? To further investigate the face specificity of the observed encoding biases, we explored whether they generalize to non-category-selective high-level regions such as the Lateral Occipital (LO) cortex. The present fMRI experiment addresses these questions, by exploring the cortical responses to distinct orientation ranges of face information at the lower and higher ends of the visual hierarchy (V1, OFA and FFA, respectively). The present study is among the first to address orientation-selective encoding in the human visual system using naturalistic stimuli.

Our participants viewed blocks of face images that were filtered in the Fourier domain to let information pass in a narrow 
orientation range centered on horizontal, left oblique, vertical or right oblique orientation (Fig. 1). The same filtered images were viewed upright, inverted and (phase-)scrambled. We first compared the orientation selectivity profiles across stimulus types (upright, inverted and scrambled faces) in order to determine whether activation differences across orientations in V1, OFA and FFA stem from face-specialized processing (i.e., selectively engaged for processing upright faces), general shape processes (i.e. as active for upright as for inverted faces), or from an even more general processing bias that is blind to stimulus shape properties (i.e., also engaged for scrambled faces). Second, we compared stimulus-selective responses across orientation ranges to address the information best driving activation differences across stimulus types in V1, OFA and FFA. Orientation may indeed affect the difference in activation between upright, inverted and scrambled faces more than the absolute activation to each stimulus type. Since the functional contribution of each cortical region may manifest itself either by modulations of its mean response (averaged across voxels) or by more subtle changes in the spatial activation pattern of its composing voxels, we investigated orientation-and stimulusselective responses in V1, OFA and FFA by means of univariate and multivoxel pattern analyses (MVPA; Haynes and Rees, 2006).

\section{Materials and methods}

\subsection{Participants}

Eight healthy faculty members of Maastricht University (mean age: $29.25 \pm 4.7 \mathrm{sd}$ ) participated in the fMRI experiments in exchange of monetary remuneration (10 euros for $1 \mathrm{~h}$ of participation). All subjects were right-handed, one of them was male. They reported normal or corrected-to-normal vision. They provided their written informed consent prior to participation. They were naïve to the purpose of the experiments. The experimental protocol was approved by the local ethical committee of Maastricht University (ECP number: 7-11-2004). Participants took part in three experiments in the scanner (a localizer, a polar retinotopic mapping and the main experiments) and one behavioral experiment outside the scanner.

\subsection{Stimuli}

In all experiments except the retinotopic mapping, participants were presented with pictures of unfamiliar adult Caucasian faces (half males, posing full-front with a neutral expression in each experiment). Different sets of face pictures were used across experiments. Face pictures were edited to eliminate external cues to facial identity (e.g., hair, ears, and neck).

The main fMRI experiment employed 40 face pictures (image size: $400 \times 500$ pixels; visual angle: $\left.9^{\circ} \times 11^{\circ}\right)$. We first subtracted the mean luminance value from each image. Then, we generated filtered stimuli by Fast Fourier transforming the original image using Matlab 7.0.1 and multiplying the Fourier energy with a wrapped Gaussian filter centered either on vertical $\left(0^{\circ}\right)$, left oblique $\left(45^{\circ}\right)$, horizontal $\left(90^{\circ}\right)$, and right oblique $\left(135^{\circ}\right)$ orientation with a bandwidth (standard deviation) of $20^{\circ}$. This bandwidth broadly matched the orientation tuning bandwidth of V1 neurons (e.g., Ringach, et al., 2002; Vogels and Orban, 1990). Filtering allows all SFs to pass within a restricted orientation range. In addition to filtering, the phase of the face images was randomly permuted in the Fourier domain, a procedure known to prevent the image recognition while preserving its SF and orientation content (Goffaux et al., 2011a). After the inverse Fourier transform, the global luminance and root-mean square (RMS) contrast of each filtered image was adjusted to match the average global luminance and RMS contrast of the original image set. Inverted stimuli were generated by vertically flipping each image.

In the localizer, twenty face, twenty car and twenty natural scene (van der Schaaf et al., 1996) grayscale images were presented in upright and phase-scrambled versions. Image size was $256 \times 256$ pixels (visual angle of $5.8^{\circ} \times 5.8^{\circ}$ ). A light gray border of 3 pixels surrounded all stimuli. The luminance and RMS contrast of all stimuli were adjusted to match mean luminance and contrast values of the whole image set.

During fMRI scanning, stimuli were projected onto a translucent screen at the rear end of the scanner bore by means of a LCD projector (resolution of $1024 \times 768$ pixels) and viewed by the subjects through a mirror placed within the RF coil at a viewing distance of $57 \mathrm{~cm}$. Behavioural responses were collected during acquisition via a button box.

The behavioral experiment performed outside the scanner employed grayscale $190 \times 250$ pixel face pictures. We used the same filtering procedure as for the main fMRI experiment. Stimuli were displayed on a gray background on a LCD screen using E-prime 1.1 (screen resolution: $1024 \times 768$, refresh rate: $60 \mathrm{~Hz}$ ). Viewed at a distance of $60 \mathrm{~cm}$, stimuli subtended a visual angle of $6.6^{\circ} \times 8.7^{\circ}$.

\subsection{Procedure}

In the main experiment, there were twelve experimental conditions (three stimulus types: upright, inverted, and scrambled by four orientation ranges: $0^{\circ}, 45^{\circ}, 90^{\circ}$, and $135^{\circ}$ ). Participants were presented with 6 -s blocks of 12 stimuli. Each stimulus appeared for $300 \mathrm{~ms}$ at the center of the screen, followed by a $200 \mathrm{~ms}$ blank. Blocks were separated by fixation pauses of randomly jittered duration ( 6,8 or $10 \mathrm{~s}$ ). There were 5 blocks per condition per run and four runs, making a total of 20 blocks per condition.

Participants were instructed to fixate on a yellow central cross along the run and to press with their right index finger whenever they detected a red-colorized stimulus. Red-colorized stimuli were generated by increasing the red channel intensity of each filtered face image by 10 percent. There were up to two targets per block and the same number of targets for all conditions in total. Each run started with an average fixation of $14 \mathrm{~s}$ (range: 12-16 s) and ended with a 10-s fixation period. The orthogonal color detection task ensured participant's vigilance during the experiment while keeping equal levels of arousal and performance across conditions. The perceptual sensitivity of our participants to the different orientation range by stimulus type conditions was addressed in the behavioral experiment performed later and outside the scanner.

The localizer experiment comprised two runs, each comprising thirty 12 s blocks of 20 images: either faces, cars, scenes, scrambled faces, scrambled cars, or scrambled scenes. Within a block, each stimulus appeared during $400 \mathrm{~ms}$ at screen center, followed by a blank screen of $200 \mathrm{~ms}$. Participants had to fixate on the yellow fixation cross during the run. Akin to the main experiment, they had to react to red-colorized stimuli (one or two occurrences per block). Blocks were interleaved with fixation periods lasting $12 \mathrm{~s}$ on average (duration range: $10-14 \mathrm{~s}$ ). There were 10 blocks per condition in total. A localizer run started and ended with fixation of 18 (range: 16-20) and $12 \mathrm{~s}$, respectively.

In order to delineate V1 borders in each individual, each participant performed a polar retinotopic experiment (Sereno et al., $1995,1994)$. A rotating wedge with a black and white checkerboard pattern completed a full rotation within $64 \mathrm{~s}$. Each retinotopic run started with a 12-s fixation followed by 8 cycles of wedge rotation and ended with another 12-s fixation. Each participant completed two polar angle runs. 
Table 1

ROI Talairach coordinates (group mean and standard deviation).

\begin{tabular}{llrlllll}
\hline ROI & Mean $x$ & (std) & Mean $y$ & (std) & Mean $z$ & (std) & Mean n voxels \\
\hline V1 & 0 & 2 & -89 & 3 & 1 & 4 & 6372 \\
rOFA & 36 & 3 & -73 & 6 & -5 & 4 & 579 \\
IOFA & -38 & 20 & -73 & 4 & -2 & 7 & 627 \\
rFFA & 37 & 2 & -46 & 7 & -13 & 3 & 990 \\
lFFA & -40 & 3 & -48 & 6 & -16 & 3 & 776 \\
\hline
\end{tabular}

\section{4. fMRI acquisition}

Imaging was performed on a 3T head scanner at Maastricht University (Allegra, Siemens Medical Systems, Erlangen, Germany) provided with an eight-channel head coil. T2*-weighted echoplanar imaging (EPI) was performed using BOLD contrast as an indirect marker of local neuronal activity. In the main experiment and retinotopic runs, twenty-eight $2 \mathrm{~mm}$ oblique coronal slices were acquired $(0.2 \mathrm{~mm}$ gap in the main experiment runs and no gap in the retinotopic runs, $\mathrm{TR}=2000 \mathrm{~ms}, \mathrm{TE}=30 \mathrm{~ms}$, matrix size $=112 \times 112, \quad F O V=224 \mathrm{~mm}$, in-plane resolution $2 \times 2 \mathrm{~mm}^{2}$ ). One run of the main experiment lasted for 420 volumes ( $14 \mathrm{~min}$ ) and each retinotopic run consisted in 268 volumes ( $8.9 \mathrm{~min}$ ).

In the localizer, thirty-two $3.5 \mathrm{~mm}$ oblique coronal slices were acquired (no gap, $\mathrm{TR}=2000 \mathrm{~ms}, \mathrm{TE}=30 \mathrm{~ms}$, matrix size $=64 \times 64$, $\mathrm{FOV}=224 \mathrm{~mm}$, in-plane resolution $3.5 \times 3.5 \mathrm{~mm}^{2}$ ). One localizer run was 382 TRs long (12.7 $\mathrm{min})$.

A high-resolution T1-weighted anatomical data set was acquired in each session (ADNI sequence, $T R=2250 \mathrm{~ms}, \mathrm{TE}=26 \mathrm{~ms}$, Flip angle $=9^{\circ}$, matrix size $=256 \times 256, F O V=256 \mathrm{~mm}^{2}, 192$ slices, slice thickness $=1 \mathrm{~mm}$, no gap, total run time $=8 \mathrm{~min} 26 \mathrm{~s}$ ).

\section{5. fMRI data processing}

Functional and anatomical images were analysed using BrainVoyager QX (version 2.4, Brain Innovation, Maastricht, The Netherland; Goebel et al., 2006). The first four volumes were skipped to avoid T1 saturation effects. Functional runs underwent several pre-processing steps: correction of inter-slice scan time differences; linear trend removal; temporal high-pass filtering (to remove frequencies lower than two cycles per time course), and correction for head motion. We did not make use of spatial smoothing.

Anatomical and functional data were spatially normalized to the Talairach coordinate system (Talairach and Tournoux, 1988) using sinc interpolation. Spatial resolution was of $3 \mathrm{~mm} \times 3 \mathrm{~mm} \times 3 \mathrm{~mm}$ isotropic in the localizer and of $2 \mathrm{~mm} \times 2 \mathrm{~mm} \times 2 \mathrm{~mm}$ in the retinotopic mapping and the main experiment.

We reconstructed the cortical surface of each individual by semi-automatically segmenting white and gray matter based on anatomical scan (Goebel et al., 2006; Kriegeskorte and Goebel, 2001). The cortical surface was then inflated and flattened.

\subsection{ROI definition}

For each participant, V1 was localized on the flattened cortical surface based on the linear cross-correlation analysis of individual retinotopic mapping data (Sereno et al., 1995). The visual cortex was cut manually along the calcarine sulcus following the cortical representation of the horizontal and vertical meridians (as in van de Ven et al., 2012).

OFA and FFA regions were defined in each individual based on the localizer data. The localizer data of each subject were analyzed using an individual fixed effect (FFX) general linear model (GLM). The predictor time courses for stimulation blocks were constructed as box-car functions filtered through a double gamma HRF model indirectly relating neural activity and BOLD response (Boynton et al., 1996). For anatomical reference, the statistical maps were overlaid on Talairach-normalized averaged anatomical volumes. Left- and right-lateralized OFA and FFA were defined by the conjunction of the [Faces - Cars], [Faces - Scenes], [Faces Scrambled Faces] contrasts (Rossion et al., 2012a). Significant voxel clusters $(q<.05$; corrected by False Discovery Rate, FDR) on the resulting individual $F$ maps were selected as ROIs for further analysis. Bilateral FFA, right OFA, and V1 could be localized in each subject but we found left OFA in 7 out of the 8 subjects.

Talairach coordinates of ROIs were consistent with previous studies (see Table 1).

\subsection{ROI statistical analyses}

\subsubsection{Univariate analyses}

We extracted averaged z-scored beta weights from each individual ROI for each block of the main experiment. Unless pilot analyses indicated that hemispheric lateralization modulated significantly the influence of Stimulus type or Orientation range, we collapsed data across hemispheres and performed an omnibus repeated-measure ANOVA with Stimulus type (Upright, Inverted, and Scrambled), Orientation range $\left(0^{\circ}, 45^{\circ}, 90^{\circ}\right.$, and $\left.135^{\circ}\right)$, and ROI (FFA, OFA, V1).

Whenever Mauchly's test indicated that the assumption of sphericity had been violated, degrees of freedom were adjusted following Greenhouse-Geisser correction. Post-hoc Fisher LSD tests were used for pairwise comparisons. We controlled for the multiplicity of performed tests using FDR procedure (mafdr.m function in Matlab; Benjamini and Hochberg, 1995).

\subsection{2. $M V P A$}

The beta weights of each individual block and ROI were first normalized relative to the average and standard deviation of the entire time course within each run in order to minimize baseline differences across conditions and runs and therefore to ascertain that MVPA results are not due to differences in the ROI average activation level already captured by univariate analyses. The data were further analyzed by means of linear support vector machines (SVM; Cortes and Vapnik, 1995) using custom Matlab functions (same as in Bonte et al., 2014). The data of the main experiment consisted of 20 voxel activation patterns per condition divided in four runs (in two out of 8 subjects, only 3 runs and 15 activation patterns were available). Following a leave-one-run-out cross-validation procedure, the data were divided in two parts, one used to train the SVM classifier (three randomly selected runs) and the remaining run to evaluate how well the classification model generalized (evaluation set). Based on this procedure, we tested (1) orientation- and (2) stimulus-selective encoding in V1 and bilateral FFA regions.

We assessed orientation selectivity of each ROI by testing the ability of the SVM to differentiate between pairs of orientation condition $\left(0^{\circ}\right.$ versus $45^{\circ}, 0^{\circ}$ versus $90^{\circ}, 0^{\circ}$ versus $135^{\circ}, 45^{\circ}$ versus $135^{\circ}, 45^{\circ}$ versus $90^{\circ}$, and $90^{\circ}$ versus $135^{\circ}$ ) based on the spatial pattern of voxel activation. We ran the six binary orientation classifiers in each stimulus type separately (upright, inverted, or scrambled).

Stimulus-selective encoding was evaluated in each ROI based on SVM accuracy in distinguishing pairs of stimulus types (Upright versus Scrambled, Inverted versus Scrambled, and Upright versus Inverted) based on the spatial activation pattern. These three binary stimulus classifiers were run in each orientation range separately.

Pairwise classification accuracies were not aggregated because our goal was to explore the detailed profiles of orientation and stimulus selectivity in each ROI. As for univariate analyses, we 
collapsed decoding accuracy across hemispheres unless pilot analyses revealed that hemispheric lateralization modulated the influence of the other factors and performed an omnibus repeated-measure ANOVA with Classification pair, Stimulus type or Orientation range depending on whether orientation content or stimulus type was decoded, and ROI (FFA, OFA, V1). Post-hoc tests were performed following the same procedure as for univariate analyses.
To assess whether our classification accuracies significantly differed from chance level, we used a permutation test (Nichols and Holmes, 2002). For this purpose, the same SVM classification models used for the experimental data were repeated 500 times per subject, with scrambled trial labels. The empirical chance level for each condition (stimulus type for orientation classification and orientation content for category classification) in each subject was obtained by averaging the accuracy over the 500 iterations. We

\section{a. Mean activation}
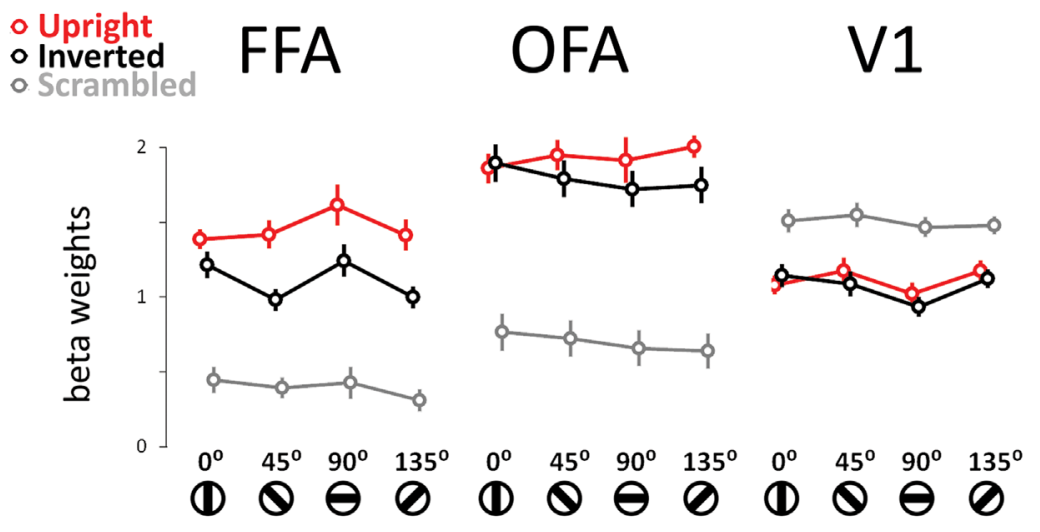

b. Orientation Decoding

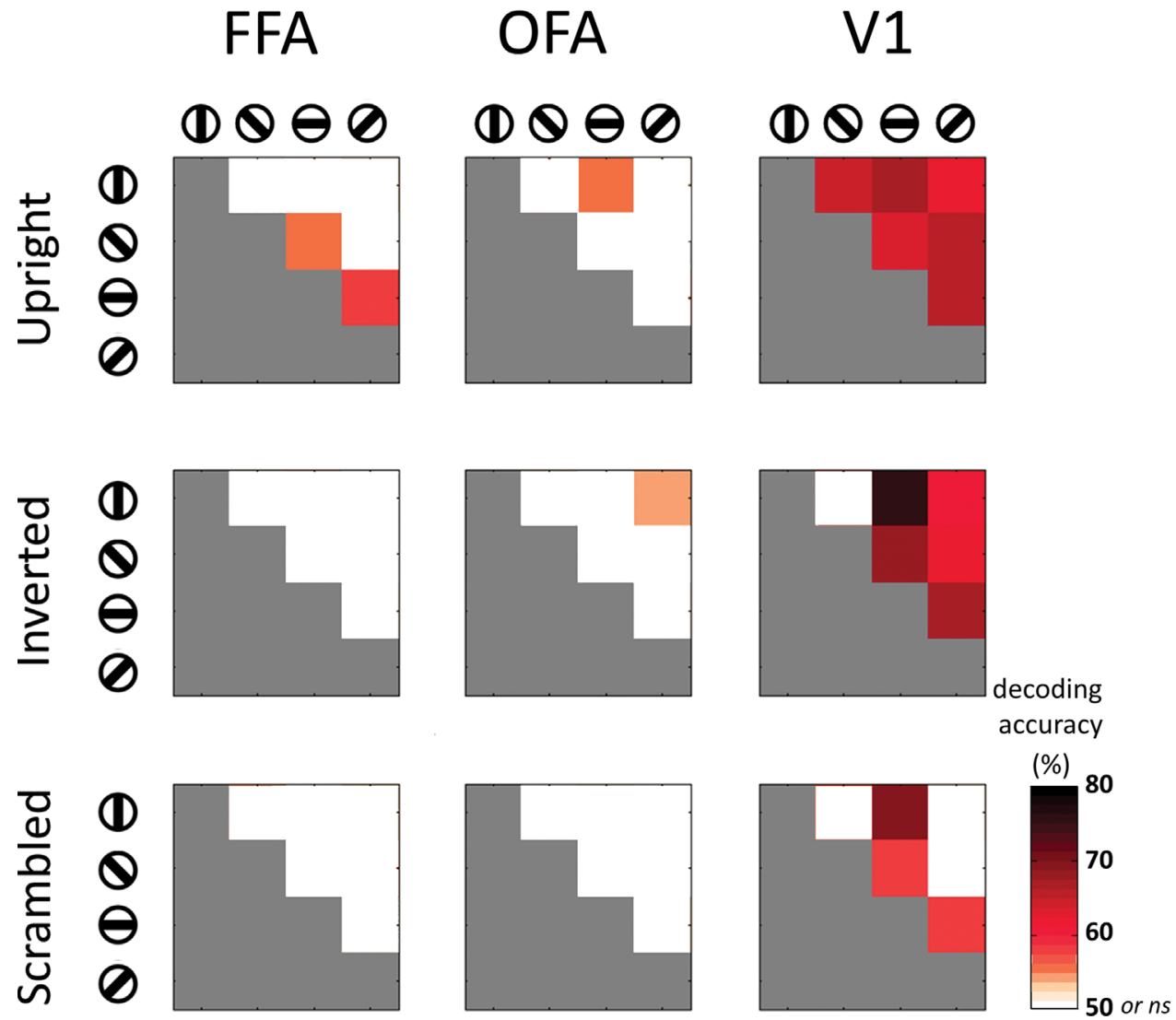

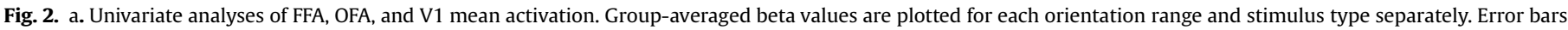

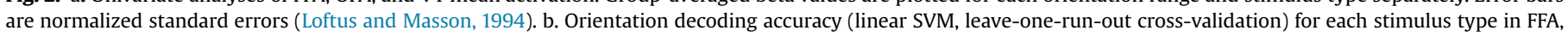

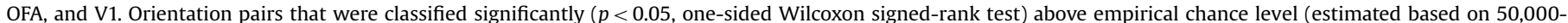
iterative permutation test) are color-coded. (For interpretation of the references to color in this figure legend, the reader is referred to the web version of this article.) 
assessed whether group-level SVM performance significantly differed from the empirical chance level $\left(\mathrm{H}_{0}\right.$ being that accuracy is not higher than empirical chance level) by running one-tailed Wilcoxon signed rank tests (Fatal-Weber and Sawilowsky, 2009).

\section{Results}

\subsection{Univariate analyses}

Fig. 2a shows the average response of V1, bilateral OFA and FFA for the different stimulus types across orientations. Pilot analyses revealed an overall stronger activity in the right than the left FFA $\left(F(1,7)=7.1, p<.03, \eta^{2}=.5\right)$. There was no other influence of hemispheric lateralization neither in OFA, nor FFA average responses (all ps $>.1$ ), we therefore collapsed the data across hemispheres. Z-scored beta weights were submitted to an omnibus repeated-measure ANOVA with ROI (V1, OFA, FFA), Stimulus type (Upright, Inverted, Scrambled), and Orientation range $\left(0^{\circ}\right.$, $\left.45^{\circ}, 90^{\circ}, 135^{\circ}\right)$. Main effects of ROI and Stimulus type were significant $\left(F(2,14)=3.9, \quad p<.046, \quad \eta^{2}=.36\right.$ and $F(2,14)=42.2$, $p<.00001, \eta^{2}=.86$, respectively) but qualified by a two-way interaction $\left(F(1.8,12.9)=47, p<.00001, \eta^{2}=.87\right)$. The ROI by Orientation interaction was also significant $(F(6,42)=6.35, p<.0001$, $\left.\eta^{2}=.5\right)$. We explored these two-way interactions by running separate ANOVAs per ROI.

In the FFA, the main effects of Stimulus type and Orientation were significant $\left(F(2,14)=49.5, p<.00001, \eta^{2}=.9\right.$ and $F(3,21)=$ $6.3, p<.003, \eta^{2}=.5$, respectively) and qualified by a significant interaction $\left(F(6,42)=2.53, p<.035, \eta^{2}=.26\right)$. When faces were upright, the horizontal range (i.e., the $90^{\circ}$ condition) elicited the strongest FFA activity compared to all other orientations (qs $($ FDR $)<.009)$. The other orientation ranges did not differ significantly from each other (all qs(FDR $>.7)$. When faces were inverted, cardinal orientations $\left(0^{\circ}\right.$ and $\left.90^{\circ}\right)$ elicited a significantly stronger FFA response than oblique orientations $\left(45^{\circ}\right.$ and $135^{\circ}$; qs $($ FDR $)<.004)$. There was no significant activity difference within cardinal and oblique orientations (all qs(FDR) $>.7$ ). When faces were scrambled, the different orientation ranges resulted in comparable activation levels $(\mathrm{qs}(\mathrm{FDR})>.06)$. To sum up, FFA average activation is tuned to horizontal information only when faces were upright. This activation profile strikingly mirrors the past and present behavioral findings that face perception is best based on horizontal compared to vertical information but only under upright viewing conditions (Goffaux and Dakin, 2010; Goffaux et al., 2011b; Supplementary file 1; Fig. 1).

We dissected the two-way interaction the other way around, by testing the influence of stimulus type for each orientation range, separately. Scrambling and inversion significantly reduced FFA response, in all orientation ranges $(\mathrm{qs}(\mathrm{FDR})<.02)^{1}$. The size of the face inversion effect (FIE) was the weakest in the vertical range (FIE Cohen's d at $0^{\circ}: .26,45^{\circ}: .7,90^{\circ}: .55,135^{\circ}: .6$ ), in agreement with previous evidence that the FIE is mainly due to the disrupted encoding of horizontal information (Goffaux and Dakin, 2010; Jacques et al., 2014; Pachai, et al., 2013). That the face-specialized computations taking place in the FFA also substantially rely on left and right oblique ranges is a novel finding.

In the OFA, the main effect of Stimulus type was significant ( $F$ $\left.(1.05,7.4)=45.8, p<.002, \eta^{2}=.87\right)$ as scrambled faces induced a significantly weaker response than upright and inverted faces (qs

\footnotetext{
${ }^{1}$ It is important to note that the vertical flip of the image that we used in order to create inverted faces turned each oblique orientation into its orthogonal counterpart. Nevertheless, FFA regions were not sensitive to the left/right direction of oblique information as attested by the comparable activation levels to left- and right-oblique orientations in upright and inverted faces.
}

$($ FDR $)<.00001)$. The latter conditions did not differ in activation level $(\mathrm{q}(\mathrm{FDR})=.3)$. Neither the main effect of Orientation, nor the two-way Orientation by Stimulus type interaction were significant (Fs $<1.8$, ps $>.13, \eta^{2}<.2$ ).

In contrast to FFA and OFA, V1 responded most robustly to scrambled faces compared to upright and inverted faces (Fig. 2a, main effect of Stimulus Type: $F(2,14)=27.6, p<.0001, \eta^{2}=.8$; scrambled versus upright: $\mathrm{q}(\mathrm{FDR})<.00004$; scrambled versus inverted: $\mathrm{q}(\mathrm{FDR})<.00001)$. There was no significant inversion effect in V1 (upright versus inverted: $\mathrm{q}(\mathrm{FDR})=.53$ ).

This region further contrasted with FFA in that its response to $90^{\circ}$ stimuli was significantly weaker than to $45^{\circ}$ and $135^{\circ}$ stimuli (main effect of Orientation range: $\left(F(3,21)=3.6, p<.03, \eta^{2}=.34\right.$; $45^{\circ}$ versus $90^{\circ}$ and $135^{\circ}$ versus $\left.90^{\circ}: \mathrm{qS}(\mathrm{FDR})<.045\right)$; it was also marginally weaker than to $0^{\circ}$ stimuli $(\mathrm{q}(\mathrm{FDR})=.06)$. There was no $\mathrm{V} 1$ activation difference between the other orientations (between $0^{\circ}, 45^{\circ}$, and $135^{\circ}$ : all $\mathrm{qS}(\mathrm{FDR})>.8$ ).

Do the above findings reflect encoding biases that are specific to the processing of faces, or do they generalize to non-categoryselective high-level regions such as the lateral occipital (LO)? As expected, LO responded more strongly to intact (i.e., upright and inverted faces) than to scrambled viewing conditions. It did not reveal any FIE, further confirming its non-specialized contribution to face processing. In contrast to FFA, bilateral LO tended to respond more largely to vertical information and this orientation selectivity was not modulated by stimulus type (see Supplementary file 2 for a detailed result description).

\subsection{Orientation decoding}

The univariate analyses above revealed the orientation and stimulus type selectivity profile of low- and high-level visual regions at a macroscopic level (i.e., mean activation level). The MVPA below explore whether the selectivity of these regions to orientation and stimulus type may manifests itself by finer-grained modulations of their spatial activation pattern.

First, we addressed the influence of the Classification pair $\left(0^{\circ}\right.$ versus $90^{\circ}, 0^{\circ}$ versus $45^{\circ}, 0^{\circ}$ versus $135^{\circ}, 45^{\circ}$ versus $135^{\circ}, 90^{\circ}$ versus $45^{\circ}, 90^{\circ}$ versus $135^{\circ}$ ), Stimulus type (Upright, Inverted, Scrambled), and ROI (V1, OFA, FFA) on orientation decoding accuracy via an omnibus repeated-measure ANOVA. Since pilot analyses did not reveal any influence of hemisphere lateralization neither in FFA, nor in OFA (Fs $<.18$, ps $>.2, \eta^{2}<.2$ ), data were collapsed across hemispheres in Fig. 2b and the analyses below. However, decoding accuracies per hemisphere are available in the Supplementary file 3.

The main effect of ROI was significant $(F(2,14)=31.5$, $\left.p<.00001, \eta^{2}=.82\right)$; orientation decoding was overall most reliable in V1 compared to OFA and FFA (qS(FDR) $<.0001)$, but of comparable accuracy between OFA and FFA (q (FDR)=.6). Decoding accuracy was also influenced by Classification pair $(F(5,35)=$ $6.5, p<.0002, \eta^{2}=.48$ ) with the classification of $0^{\circ}$ versus $90^{\circ}$ pair being more accurate than others $(\mathrm{qs}(\mathrm{FDR})<.03)$ except the $90^{\circ}$ versus $135^{\circ}$ pair $(\mathrm{q}(\mathrm{FDR})<.2)$. These effects were qualified by a significant ROI by Classification pair interaction $(F(10,70)=2.13$, $p<.03, \eta^{2}=.23$ ). In the following, we report the results of the ANOVA performed on each ROI, separately, along with the statistical comparison of decoding accuracy to empirical chance level (based on one-sided Wilcoxon sign-rank test; Fig. 2b).

In bilateral FFA, there was no significant difference in orientation decoding accuracy across classification pairs or stimulus types (Fs $<1.5$, ps $>.25, \eta^{2}<.17$ ). Orientation decoding in this region was significantly above chance level for the discrimination of horizontal against each oblique range for upright faces only $\left(90^{\circ}\right.$ versus $45^{\circ}$ and $90^{\circ}$ versus $135^{\circ}$; $56 \%$ accuracy on average; $\mathrm{ps}<.03$; Fig. $2 \mathrm{~b}$ ). The decoding of $0^{\circ}$ versus $90^{\circ}$ upright face information was marginal $(p=.07)$. 
In bilateral OFA, the main effect of Classification pair was significant as decoding was significantly worse for $45^{\circ}$ versus $135^{\circ}$ than for all other classifications $(\mathrm{qs}(\mathrm{FDR})<.036)$ except the $90^{\circ}$ versus $135^{\circ}$ pair $(\mathrm{qS}(\mathrm{FDR})=.13)$. Activation patterns reliably differed between cardinal orientations $\left(0^{\circ}\right.$ versus $\left.90^{\circ}: p<.027\right)$ but only for upright faces. For inverted faces, the $0^{\circ}$ versus $135^{\circ}$ classification was the only to surpass chance level ( $p s<.012$ ).

In V1, most orientation pairs were classified well above chance in upright and inverted conditions (Fig. 2B; Supplementary file 3; all ps $<.03 ; 0^{\circ}$ versus $45^{\circ}$ in inverted faces: $\left.p=.054\right)$. In contrast, when faces were scrambled, decoding failed for half of the orientation pairs $\left(45^{\circ}\right.$ versus $135^{\circ}: p=.27 ; 0^{\circ}$ versus $135^{\circ}: p=.054 ; 0^{\circ}$ versus $45^{\circ}$ orientations; $p=.4$; other orientation discrimination: all ps $<.012)$. Besides a significant main effect of Classification pair $(F$ $\left.(5,35)=4.55, p<.003, \eta^{2}=.4\right)$, the ANOVA disclosed a marginal but non-negligible interaction between Classification pair and Stimulus type $\left(F(10,70)=1.8, p=.08, \eta^{2}=.2\right)$. Whereas the accuracy for decoding $0^{\circ}$ versus $90^{\circ}$ was comparable to other classification pairs for upright faces ( $\mathrm{qs}(\mathrm{FDR})>.3$ ), it was more accurate than for $0^{\circ}$ versus $45^{\circ}, 0^{\circ}$ versus $135^{\circ}$, and $45^{\circ}$ versus $135^{\circ}$ pairs for inverted faces (qs(FDR) <.009), and most accurate overall when faces were scrambled $(\mathrm{qs}(\mathrm{FDR})<.03)$. The decoding of $45^{\circ}$ versus $135^{\circ}$ oriented content significantly decreased from upright to inverted and from inverted to scrambled conditions (qs $(\mathrm{FDR})<.014)$. These findings indicate that orientation selectivity in $\mathrm{V} 1$ is influenced by stimulus structure.
In bilateral LO, orientation decoding was at chance level for upright and inverted faces; when processing scrambled faces, it surpassed chance for $0^{\circ}$ versus $45^{\circ}, 90^{\circ}$ versus $45^{\circ}$, and $90^{\circ}$ versus $135^{\circ}$ pairs (Supplementary file 2 for details). However, the ANOVA did not reveal any systematic influence of Classification pair, nor of Stimulus type.

\subsection{Stimulus type decoding}

We addressed the accuracy with which stimulus type could be decoded based on the spatial activation pattern it elicited in bilateral FFA, OFA, and V1 as a function of orientation (Fig. 3; Supplementary file 4). To do so, we ran Upright versus Scrambled, Inverted versus Scrambled, and Upright versus Inverted (binary) classifications in each orientation range. Stimulus decoding accuracy was submitted to an omnibus repeated-measure ANOVA to address the influence of Classification pair (Upright versus Scrambled, Inverted versus Scrambled, Upright versus Inverted), Orientation range $\left(0^{\circ}, 45^{\circ}, 90^{\circ}, 135^{\circ}\right)$, and ROI (rFFA, IFFA, OFA, V1). Right and left FFA were kept separate because pilot analyses revealed a significant effect and interaction involving the hemispheric lateralization (see below).

Stimulus decoding was overall best in V1 (main effect of ROI: $F$ $(3,21)=8.8, p<.0006, \eta^{2}=.56$, qs(FDR $\left.)<.03\right)$; it was also better in the bilateral OFA than in the left $F F A(q(F D R)=.043)$. Decoding performance was comparable across other ROIs (qS(FDR) >.14).
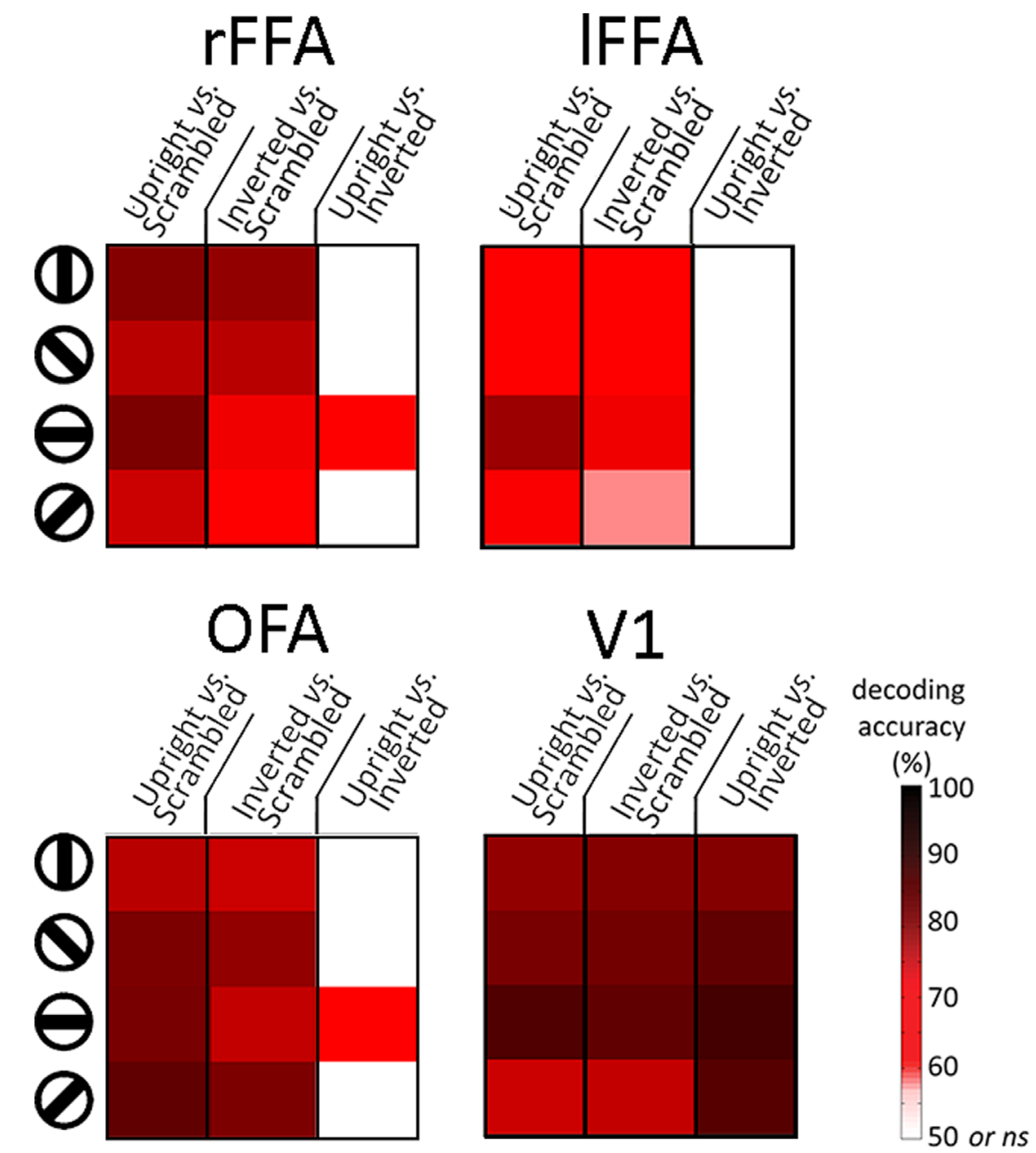

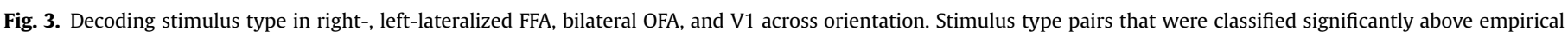

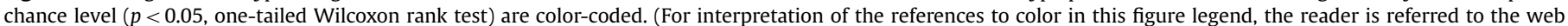
version of this article.) 
Main effects of Classification pair and of Orientation range were also significant $\left(F(2,14)=40, p<.00001, \eta^{2}=.85\right.$ and $F(1.5,10.7)=$ $4.4, p<.05, \eta^{2}=.38$, respectively). The two-way ROI by Classification pair as well as the three-way ROI by Classification pair by Orientation interactions were significant $(F(6,42)=14.4$, $p<.00001, \eta^{2}=.67$ and $F(18,126)=1.8, p<.035, \eta^{2}=.2$, respectively). In the following, we report the results of the ANOVA performed on each ROI, separately, along with the statistical comparison of decoding accuracy to empirical chance level (one-sided Wilcoxon sign-rank test).

In the FFA, the main effect of Classification pair was significant $\left(F(2,14)=29, p<.0001, \eta^{2}=.8\right)$. The interaction between Classification pair and Hemisphere lateralization and between Classification pair, Orientation and Hemisphere were also significant ( $F$ $(2,14)=4.1, \mathrm{p}<.04, \eta^{2}=.37$ and $\left.F(6,42)=2.4, \mathrm{p}<.044, \eta^{2}=.25\right)$.

In the right FFA, both the main effect of Classification pair and the Classification pair by Orientation interaction were significant $\left(F(2,14)=33, p<.00001, \eta^{2}=.82\right.$ and $F(6,42)=2.7, p<.024$, $\eta^{2}=.28$ ). Upright and inverted faces could be reliably distinguished from scrambled faces in all orientation ranges (Upright versus Scrambled: all ps $<.012$ and Inverted versus Scrambled: all ps $<.0195$, respectively), and more accurately than the decoding of Upright versus Inverted faces $(\mathrm{qs}(\mathrm{FDR})<.035)$. Interestingly, Upright versus Scrambled classification was better than Inverted versus Scrambled classification at $90^{\circ}(\mathrm{q}(\mathrm{FDR})<.04)$ but not at other angles $(\mathrm{qs}(\mathrm{FDR})>.3)$. Upright versus Inverted classification accuracy surpassed chance level only when based on horizontal information $(p<.027)$. It was also significantly better at $90^{\circ}$ than at $0^{\circ}$ and $45^{\circ}(\mathrm{qs}(\mathrm{FDR})<.03)$ but not than at $135^{\circ}(\mathrm{q}(\mathrm{FDR})=.5)$. Upright and inverted faces induced similar activation patterns in the other orientation ranges (all ps $>.16$ ), which led to comparable stimulus decoding accuracies $(\mathrm{qs}(\mathrm{FDR})>.12$ ). These findings support the privileged status of horizontal angles for the specialized processing of upright face information in the rFFA.

In the left FFA, the main effect of Classification pair was also significant $\left(F(2,14)=11.6, p<.001, \eta^{2}=.62\right)$ as Upright versus Scrambled and Inverted versus Scrambled classifications were above chance at all orientations (Upright versus Scrambled: all ps $<.008$ and Inverted versus Scrambled: all ps $<.04$ ), and more accurate than Upright versus Inverted classification (qs $($ FDR $)<.03)$, which was, in contrast, at chance level in all orientation ranges (all ps $>.055$ ). Interestingly, Upright versus Scrambled decoding was overall more accurate than Inverted versus Scrambled decoding ( $\mathrm{q}(\mathrm{FDR})<.043$ ), indirectly marking the enaggement of IFFA in upright face-specialized processes.

Stimulus decoding in OFA was not influenced by Orientation range, nor by Hemipshere (Fs $<1.7$, ps $>.15, \eta^{2}<.2$ ). Only the main effect of Classification pair was significant $(F(2,12)=32$, $p<.0001, \eta^{2}=.8$ ); Upright versus Scrambled and Inverted versus Scrambled classifications were comparably accurate $(\mathrm{q}(\mathrm{FDR})=.8)$ and more reliable than Upright versus Inverted classification (qs $($ FDR $<.0001)$. Whereas Upright versus Scrambled and Inverted versus Scrambled classifications were reliable across all orientation ranges (80\% accuracy on average; all ps $<.008$; one-sided Wilcoxon rank test), Upright versus Inverted classification only surpassed chance when based on horizontal orientation $(\mathrm{p}<.004$; at other orientation angles: ps $>.07$ ), as found in the right FFA.

In V1, stimulus type classification was above chance level at all orientations (accuracy $>83 \%$; ps $<.004$; Fig. 3 and Supplementary file 4). In contrast to FFA and OFA, Upright versus Inverted decoding was more accurate than Upright versus Scrambled and Inverted versus Scrambled decoding $(F(2,14)=7.5, p<.006$, $\eta^{2}=.52$, qs(FDR $\left.<.008\right)$, which resulted in comparable accuracies $(\mathrm{q}(\mathrm{FDR})=1)$. There was also a main effect of Orientation $(F(3,21)=$ $\left.4, p<.02, \eta^{2}=.4\right)$ as Stimulus decoding was overall better at $90^{\circ}$ than at $0^{\circ}$ and $135^{\circ}\left(\mathrm{qs}(\mathrm{FDR})<.04 ; 90^{\circ}\right.$ versus $\left.45^{\circ}: \mathrm{q}(\mathrm{FDR})=.24\right)$.
In bilateral LO, Upright versus Scrambled and Inverted versus Scrambled discriminations were highly reliable and more accurate than Upright versus Inverted classification, which was at chance in all orientations (detailed results in Supplementary file 2).

\section{Discussion}

The present findings indicate that the horizontal tuning of face perception emerges at high-level visual stages of face-specialized processing. FFA responded most strongly to the horizontal range of upright face information. The spatial activation patterns of this region only reliably separated horizontal from oblique ranges of upright face information. Horizontal tuning in FFA was disrupted by inversion; hence, the FFA response to inverted faces was not horizontally-tuned but more generally biased towards cardinal orientations. Inversion decreased FFA average response in all but the vertical orientation range. Additionally, differences in activation patterns between upright and scrambled face viewing were more robust than between when viewing inverted faces; this difference was significant across all orientation ranges in the left FFA, whereas it was selective to the horizontal range in the right FFA. Finally, activation patterns induced by upright and inverted faces could only be separated based on horizontal information in the right FFA. In the left FFA, patterns of activation to upright and inverted faces were comparable across orientations. This suggests that while both the left and right FFA selectively tune to horizontal angles of upright face information at the level of their mean activation, only the right FFA (and OFA, see below) recruits different clusters of voxels for the privileged processing of horizontal upright face information. Our findings suggest that the right FFA contributes to the horizontal tuning of face-specialized processing more substantially than the left FFA and corroborate past evidence of the right hemispheric dominance of face perception (see Rossion et al., 2012b for a review).

Overall these results indicate that the FFA tunes to the horizontal orientation range selectively for the fine-grained and specialized processing of upright face information, in agreement with past behavioral and electrophysiological evidence (Goffaux and Dakin, 2010; Pachai et al., 2013). The notion that face-specialized and not general computations in FFA are driven by horizontal information is further confirmed by the finding that when faces were scrambled, FFA activation was weak and barely influenced by image orientation content and the univariate scrambling effect did not differ across orientation ranges.

Horizontal information of upright faces also underwent privileged processing in OFA. Akin to right FFA, OFA activation pattern diverged between upright and inverted conditions only in the horizontal range. This is surprising considering present and past evidence that OFA mean activation is impervious to inversion (Goffaux et al., 2009; Goffaux et al., 2013; Mazard et al., 2006; Yovel and Kanwisher, 2005). OFA is actually thought to represent the local properties of face features (Arcurio et al., 2012; Goffaux et al., 2013; Haxby et al., 2000; Liu et al., 2010), the processing of which has been shown to be relatively resistant to inversion (Goffaux, 2012; Maurer et al., 2002; McKone and Yovel, 2009; Rossion, 2008). Still, the finding that different clusters of OFA voxels responded to the processing of upright compared to inverted horizontal face information indicates that this region contributes to the specialization of horizontal face information encoding. Whether the latter finding reflects horizontal biases in the local encoding of facial features needs to be addressed in future studies.

In contrast to FFA, OFA mean activation was not orientationsensitive. Orientation decoding accuracy was also comparable across OFA and FFA regions. This is in line with recent evidence 
that OFA response is more invariant to the primary properties of the face image than FFA (e.g., size, amplitude spectrum, spatial frequency range; Goffaux et al., 2011a; Henriksson et al., 2015; Rossion et al., 2012b). Such findings (see also Jiang et al., 2011) challenge the feedforward models of vision proposing that the more anteriorly located along the ventral stream, the more invariant to primary image properties a visual region is (GrillSpector and Weiner, 2014; Haxby et al., 2000).

The lateral occipital (LO) cortex, a high-level region generally selective to complex shapes, responded most strongly to vertical angles. These observations agree with past evidence that low-level visual biases extend beyond the borders of face-preferring regions (e.g., Musel et al., 2014; Nasr and Tootell, 2012; O'Toole et al., 2005; Peyrin et al., 2004; Rajimehr et al., 2011; Rice et al., 2014; Williams et al., 2009). However, in contrast to face-preferring FFA, the orientation tuning of LO did not depend on whether the stimulus was an upright, inverted, or a scrambled face. This suggests that orientation tuning in this region emerges at a general computational level unrelated to shape processing (e.g. in PPA Nasr and Tootell, 2012). However, the use of other stimulus categories, and not just faces, will be necessary to more stringently address the orientation selectivity of LO cortex.

The horizontal tuning in high-level face-preferring cortex was not passively inherited from V1. V1 was even found to respond less strongly to horizontal than other orientations, irrespective of stimulus type. The attenuation of $\mathrm{V} 1$ response for horizontal angles may seem at odds with previous evidence that V1 activates most strongly to cardinally-oriented gratings (i.e., vertical and horizontal gratings; Furmanski and Engel, 2000; Yacoub et al., 2008) and that human visual sensitivity is best at cardinal compared to oblique orientations (see review by Maloney and Clifford, 2015). However, empirical support for a cardinal advantage has been obtained with grating stimuli. When more naturalistic stimuli are used, psychophysical research indicates that the pattern of orientation selectivity actually reverses with human sensitivity being best in the oblique, intermediate in vertical and worst in horizontal range (Essock et al., 2003; Hansen et al., 2003). The horizontal attenuation for natural scene processing has been proposed to result from a primary adaptive 'whitening' mechanism that attenuates the horizontal cues predominantly conveyed by natural scene images to devote more processing resources to the less salient (vertical and) oblique cues. Considering that face images also contain most energy at horizontal angles (Dakin and Watt, 2009; Keil, 2009), it seems plausible that the horizontal attenuation we observed in V1 reflects such an adaptive mechanism. Remarkably, our findings indicate that despite the processing of horizontal range is attenuated in $\mathrm{V} 1$, it is amplified at higher and specialized levels of face processing. The investigation of the functional relationships between primary attenuation and higherlevel amplification of orientation coding will yield new insights on how visual information is being transformed along the course of processing.

Apart from the response attenuation in the horizontal range, V1 mean activation did not differ across orientations. As expected, V1 orientation selectivity was best captured by MVPA (Haynes and Rees, 2005; Kamitani and Tong, 2005; Swisher et al., 2010). Activation patterns enabled predicting the orientation range being viewed at approximately $65 \%$ of accuracy for upright and inverted faces (chance level was at 50\%). Previous 3T fMRI studies reported higher accuracy for the decoding of similar orientation disparities in V1 (e.g., Alink et al., 2013; Haynes and Rees, 2005; Kamitani and Tong, 2005). Accuracy discrepancies across the present and past orientation decoding studies may be explained by divergences in stimulus parameters. While the orientation bandwidth of the gratings employed in previous works was of exactly $1^{\circ}$, our stimuli encompassed a $20^{\circ}$-wide range of orientations. Such a bandwidth was necessary to ascertain that faces were still visible in filtered conditions. However the drawback is that it caused a non-negligible orientation overlap in the to-be-decoded pairs and likely decreased V1 orientation decoding accuracy in the present study (see Alink et al., 2013). Stimulus contrast is another point of divergence between our and previous orientation decoding studies. Square-wave gratings used in the latter were highly contrasted whereas in the present experiment stimulus contrast matched more naturalistic, but also weaker, values. Although stimulus contrast is not expected to influence $\mathrm{V} 1$ orientation selectivity at the neuronal level (Ferster and Miller, 2000; Sclar and Freeman, 1982; Skottun et al., 1987), it is known to influence V1 BOLD response amplitude (Boynton et al., 1996) and the accuracy of grating orientation decoding (Smith et al., 2011). The naturalistic contrast values used here have therefore likely decreased the precision with which orientation could be classified compared to past works.

The present study is among the first to address orientationselective encoding in the human visual system using naturalistic stimuli. The feedforward view that V1 operates before and independently from high-level processing stages indeed led most researchers to investigate $\mathrm{V} 1$ with artificial and simplified stimuli (Olshausen and Field, 2005). The present results however indicate that V1 activation and orientation selectivity differed between upright, inverted, and scrambled viewing conditions despite matched spectral properties. While V1 average activation was weaker in response to intact (i.e., upright and inverted) than to scrambled stimuli, orientation decoding accuracy was better in the former than the latter condition. Hence, the decoding of oblique orientations decreased in accuracy from intact to scrambled viewing conditions in favor of cardinal orientations, again suggesting a decreased V1 selectivity to oblique orientations for nonnaturalistic shapes (i.e., scrambled face information or gratings). In Supplementary file 5 , we provide evidence that differences in pixel-wise dissimilarity between intact and scrambled stimuli is unlikely to explain V1 activation profile. The higher activation and lesser orientation selectivity of V1 to scrambled compared to intact images may instead be due to the particularly low sparseness of scrambled images (i.e., Dakin et al., 2002; Olman et al., 2004; Portilla and Simoncelli, 2000; Stojanoski and Cusack, 2014). Natural images are by definition sparse, i.e., they contain a high-order structure largely due to the presence of edges (Morrone and Burr, 1988), and this property in turn induces sparse V1 activation patterns. Sparse activations are advantageous because they are more discriminable and likely also better read out by subsequent processing stages (e.g., Felsen et al., 2005; Froudarakis et al., 2014; Olshausen and Field, 2004). The low sparseness of scrambled images may thus have induced less discriminable activation patterns in V1. By disrupting image sparseness, and therefore recognizability, scrambling may also have prevented high-level shape representations from guiding V1 function via recurrent feedback (de-Wit et al., 2012; Kok and de Lange, 2014; Kok et al., 2012). Hence, $V 1$ is known to respond less to edges when they form a coherent percept than when they are perceived as isolated elements (Alink et al., 2010; Dumoulin and Hess, 2006; Kok et al., 2014, 2012; Murray et al., 2002 though see Olman et al., 2004; Rieger et al., 2013; Tjan et al., 2006). A similar phenomenon may have been at stake here and explain the stronger mean V1 activation to scrambled than intact images.

Little is known on how the information is being transformed along the visual hierarchy to enable the specialized and invariant categorization of objects. By revealing that primary coding in V1 is influenced by high-order stimulus structure and that high-level processing is tuned to selective ranges of primary information, the present work suggests that primary and high-level levels of the visual system interact over processing course in order to modulate 
the processing of certain ranges of primary information depending on their relevance for the stimulus and task at hand. The use of naturalistic complex stimuli and the consideration of their primary visual properties therefore seems essential to understand how vision works (Bex and Makous, 2002; Lamme and Roelfsema, 2000; Olshausen and Field, 1996; Rust and Dicarlo, 2010).

\section{Acknowledgments}

The first author is supported by the Belgian National Fund for Scientific Research (FNRS). This work was supported by the Maastricht University, The Netherlands (36020082N, 36020054N). We are grateful to Meike Ramon for allowing us to use her database of face pictures, to Steven C. Dakin for the codes we used to filter our stimuli, to Gesa Lange for her help during the processing of retinotopic data, to Michelle Moerel and Judith Eck for their help on brain segmentation, to Joao Correira, Roberta Santoro and Anke Ley for their helpful advice on multivariate analyses, and to Kirsten Petras for thoughtful comments on previous versions of the paper.

\section{Appendix A. Supplementary material}

Supplementary data associated with this article can be found in the online version at http://dx.doi.org/10.1016/j.neuropsychologia. 2015.12.004.

\section{References}

Alink, A., Krugliak, A., Walther, A., Kriegeskorte, N., 2013. fMRI orientation decoding in $\mathrm{V} 1$ does not require global maps or globally coherent orientation stimuli. Front. Psychol. 4, 493.

Alink, A., Schwiedrzik, C.M., Kohler, A., Singer, W., Muckli, L., 2010. Stimulus predictability reduces responses in primary visual cortex. J. Neurosci.: Off. J. Soc. Neurosci. 30, 2960-2966.

Andrews, T.J., Clarke, A., Pell, P., Hartley, T., 2010. Selectivity for low-level features of objects in the human ventral stream. Neuroimage 49, 703-711.

Andrews, T.J., Davies-Thompson, J., Kingstone, A., Young, A.W., 2010. Internal and external features of the face are represented holistically in face-selective regions of visual cortex. J. Neurosci.: Off. J. Soc. Neurosci. 30, 3544-3552.

Arcurio, L.R., Gold, J.M., James, T.W., 2012. The response of face-selective cortex with single face parts and part combinations. Neuropsychologia 50, 2454-2459.

Benjamini, Y., Hochberg, Y., 1995. Controlling the false discovery rate: a practical and powerful approach to multiple testing. J. R. Stat. Soc. 57, 289-300.

Bex, P.J., Makous, W., 2002. Spatial frequency, phase, and the contrast of natural images. J. Opt. Soc. Am. A Opt. Image Sci. Vis. 19, 1096-1106.

Bonte, M., Hausfeld, L., Scharke, W., Valente, G., Formisano, E., 2014. Task-dependent decoding of speaker and vowel identity from auditory cortical response patterns. J. Neurosci.: Off. J. Soc. Neurosci. 34, 4548-4557.

Boynton, G.M., Engel, S.A., Glover, G.H., Heeger, D.J., 1996. Linear systems analysis of functional magnetic resonance imaging in human V1. J. Neurosci. 16, 4207-4221.

Cortes, C., Vapnik, V., 1995. Support-vector networks. Mach. Learn. 20, 273-297.

Dakin, S.C., Hess, R.F., Ledgeway, T., Achtman, R.L., 2002. What causes non-monotonic tuning of fMRI response to noisy images? Curr. Biol.: CB 12, R478.

Dakin, S.C., Watt, R.J., 2009. Biological "bar codes" in human faces. J. Vis. 9 (2), 1-10.

de-Wit, L.H., Kubilius, J., Wagemans, J., Op de Beeck, H.P., 2012. Bistable Gestalts reduce activity in the whole of V1, not just the retinotopically predicted parts. J. Vis. $12,1-14$.

De Valois, R.L., De Valois, K.K., 1988. Spatial Vision. Oxford University Press, New York.

Delorme, A., Thorpe, S.J., 2003. SpikeNET: an event-driven simulation package for modelling large networks of spiking neurons. Network 14, 613-627.

Dumoulin, S.O., Hess, R.F., 2006. Modulation of V1 activity by shape: image-statistics or shape-based perception? J. Neurophysiol. 95, 3654-3664.

Epstein, R., Kanwisher, N., 1998. A cortical representation of the local visual environment. Nature 392, 598-601.

Essock, E.A., DeFord, J.K., Hansen, B.C., Sinai, M.J., 2003. Oblique stimuli are seen best (not worst!) in naturalistic broad-band stimuli: a horizontal effect. Vis. Res. 43, 1329-1335.

Farah, M.J., Tanaka, J.W., Drain, H.M., 1995. What causes the face inversion effect? J. Exp. Psychol.: Hum. Percept. Perform. 21, 628-634.
Fatal-Weber, M., Sawilowsky, S.S., 2009. Comparative statistical power of the independent t, permutation t, and Wilcoxon tests. J. Mod. Appl. Stat. Methods 8 21-26.

Felleman, D.J., Van Essen, D.C., 1991. Distributed hierarchical processing in the primate cerebral cortex. Cereb. Cortex 1, 1-47.

Felsen, G., Touryan, J., Han, F., Dan, Y., 2005. Cortical sensitivity to visual features in natural scenes. PLoS Biol. 3, e342.

Ferster, D., Miller, K.D., 2000. Neural mechanisms of orientation selectivity in the visual cortex. Annu. Rev. Neurosci. 23, 441-471.

Froudarakis, E., Berens, P., Ecker, A.S., Cotton, R.J., Sinz, F.H., Yatsenko, D., Saggau, P. Bethge, M., Tolias, A.S., 2014. Population code in mouse V1 facilitates readout of natural scenes through increased sparseness. Nat. Neurosci. 17, 851-857.

Furmanski, C.S., Engel, S.A., 2000. An oblique effect in human primary visual cortex. Nat. Neurosci. 3, 535-536.

Goebel, R., Esposito, F., Formisano, E., 2006. Analysis of functional image analysis contest (FIAC) data with brainvoyager QX: from single-subject to cortically aligned group general linear model analysis and self-organizing group independent component analysis. Hum. Brain Mapp. 27, 392-401.

Goffaux, V., 2009. Spatial interactions in upright and inverted faces: re-exploration of spatial scale influence. Vis. Res. 49, 774-781.

Goffaux, V., 2012. The discriminability of local cues determines the strength of holistic face processing. Vis. Res. 64, 17-22.

Goffaux V and Dakin SC (2010) Horizontal information drives the behavioral signatures of face processing. Front. Psychology 1:143. http://dx.doi.org/10.3389/ fpsyg.2010.00143.

Goffaux, V., Peters, J., Haubrechts, J., Schiltz, C., Jansma, B., Goebel, R., 2011a. From coarse to fine? Spatial and temporal dynamics of cortical face processing. Cereb. Cortex 21, 467-476.

Goffaux, V., Rossion, B., Sorger, B., Schiltz, C., Goebel, R., 2009. Face inversion disrupts the perception of vertical relations between features in the right human occipito-temporal cortex. J. Neuropsychol. 3, 45-67.

Goffaux, V., Schiltz, C., Mur, M., Goebel, R., 2013. Local discriminability determines the strength of holistic processing for faces in the fusiform face area. Front. Psychol. 3, 604, http://dx.doi.org/10.3389/fpsyg.2012.00604.

Goffaux, V., van Zon, J., Schiltz, C., 2011b. The horizontal tuning of face perception relies on the processing of intermediate and high spatial frequencies. J. Vis., 11.

Grill-Spector, K., Weiner, K.S., 2014. The functional architecture of the ventral temporal cortex and its role in categorization. Nat. Rev. Neurosci. 15, 536-548.

Hansen, B.C., Essock, E.A., Zheng, Y., DeFord, J.K., 2003. Perceptual anisotropies in visual processing and their relation to natural image statistics. Network 14, $501-526$.

Harris, A., Aguirre, G.K., 2010. Neural tuning for face wholes and parts in human fusiform gyrus revealed by FMRI adaptation. J. Neurophysiol. 104, 336-345.

Hawken, M.J., Parker, A.J., 1987. Spatial properties of neurons in the monkey striate cortex. Proc. R. Soc. Lond. Ser. B 231, 251-288.

Haxby, J.V., Hoffman, E.A., Gobbini, M.I., 2000. The distributed human neural system for face perception. Trends Cogn. Sci. 4, 223-233.

Haynes, J.D., Rees, G., 2005. Predicting the orientation of invisible stimuli from activity in human primary visual cortex. Nat. Neurosci. 8, 686-691.

Haynes, J.D., Rees, G., 2006. Decoding mental states from brain activity in humans. Nat. Rev. Neurosci. 7, 523-534.

Henriksson, L., Mur, M., Kriegeskorte, N., 2015. Faciotopy-A face-feature map with face-like topology in the human occipital face area. Cortex 72, 156-167.

Hubel, D.H., Wiesel, T.N., 1968. Receptive fields and functional architecture of monkey striate cortex. J. Physiol. 195, 215-243.

Jacques, C., Schiltz, C., Goffaux, V., 2014. Face perception is tuned to horizontal orientation in the N170 time window. J. Vis. 14, 1-18.

James, T.W., Arcurio, L.R., Gold, J.M., 2013. Inversion effects in face-selective cortex with combinations of face parts. J. Cogn. Neurosci. 25, 455-464.

Jiang, F., Dricot, L., Weber, J., Righi, G., Tarr, M.J., Goebel, R., Rossion, B., 2011. Face categorization in visual scenes may start in a higher order area of the right fusiform gyrus: evidence from dynamic visual stimulation in neuroimaging. J. Neurophysiol. 106, 2720-2736.

Kamitani, Y., Tong, F., 2005. Decoding the visual and subjective contents of the human brain. Nat. Neurosci. 8, 679-685.

Kanwisher, N., McDermott, J., Chun, M.M., 1997. The fusiform face area: a module in human extrastriate cortex specialized for face perception. J. Neurosci. 17, 4302-4311.

Kanwisher, N., Yovel, G., 2006. The fusiform face area: a cortical region specialized for the perception of faces. Philos. Trans. R. Soc. Lond. B Biol. Sci. 361, 2109-2128.

Keil, M.S., 2009. "I look in your eyes, honey": internal face features induce spatial frequency preference for human face processing. PLoS Comput. Biol. 5, e1000329.

Kobatake, E., Tanaka, K., 1994. Neuronal selectivities to complex object features in the ventral visual pathway of the macaque cerebral cortex. J. Neurophysiol. 71 856-867.

Kok, P., de Lange, F.P., 2014. Shape perception simultaneously up- and downregulates neural activity in the primary visual cortex. Curr. Biol. 24, 1531-1535.

Kok, P., Failing, M.F., de Lange, F.P., 2014. Prior expectations evoke stimulus templates in the primary visual cortex. J. Cogn. Neurosci. 26, 1546-1554.

Kok, P., Jehee, J.F., de Lange, F.P., 2012. Less is more: expectation sharpens representations in the primary visual cortex. Neuron 75, 265-270.

Kriegeskorte, N., Goebel, R., 2001. An efficient algorithm for topologically correct segmentation of the cortical sheet in anatomical mr volumes. Neuroimage 14 , 329-346. 
Lamme, V.A., Roelfsema, P.R., 2000. The distinct modes of vision offered by feedforward and recurrent processing. Trends Neurosci. 23, 571-579.

Liu, J., Harris, A., Kanwisher, N., 2010. Perception of face parts and face configurations: an FMRI study. J. Cogn. Neurosci. 22, 203-211.

Loftus, G.R., Masson, M.E., 1994. Using confidence intervals in within-subject designs. Psychon. Bull. Rev. 1, 476-490.

Maloney, R.T., Clifford, C.W., 2015. Orientation anisotropies in human primary visual cortex depend on contrast. Neuroimage 119, 129-145.

Maurer, D., Le Grand, R., Mondloch, C.J., 2002. The many faces of configural processing. Trends Cognit. Sci. 6, 255-260.

Mazard, A., Schiltz, C., Rossion, B., 2006. Recovery from adaptation to facial identity is larger for upright than inverted faces in the human occipito-temporal cortex. Neuropsychologia 44, 912-922.

McKone, E., Kanwisher, N., Duchaine, B.C., 2007. Can generic expertise explain special processing for faces? Trends Cognit. Sci. 11, 8-15.

McKone, E., Yovel, G., 2009. Why does picture-plane inversion sometimes dissociate perception of features and spacing in faces, and sometimes not? Toward a new theory of holistic processing. Psychon. Bull. Rev. 16, 778-797.

Morrone, M.C., Burr, D.C., 1988. Feature detection in human vision: a phase-dependent energy model. Proc. R. Soc. Lond. B Biol. Sci. 235, 221-245.

Murray, S.O., Kersten, D., Olshausen, B.A., Schrater, P., Woods, D.L., 2002. Shape perception reduces activity in human primary visual cortex. Proc. Natl. Acad. Sci. USA 99, 15164-15169.

Musel, B., Kauffmann, L., Ramanoel, S., Giavarini, C., Guyader, N., Chauvin, A., Peyrin, C., 2014. Coarse-to-fine categorization of visual scenes in scene-selective cortex. J. Cogn. Neurosci. 26, 2287-2297.

Näsänen, R., 1999. Spatial frequency bandwidth used in the recognition of facial images. Vis. Res. 39, 3824-3833.

Nasr, S., Tootell, R.B., 2012. A cardinal orientation bias in scene-selective visual cortex. J. Neurosci.: Off. J. Soc. Neurosci. 32, 14921-14926.

Nichols, T.E., Holmes, A.P., 2002. Nonparametric permutation tests for functional neuroimaging: a primer with examples. Hum. Brain Mapp. 15, 1-25.

O’Toole, A.J., Jiang, F., Abdi, H., Haxby, J.V., 2005. Partially distributed representations of objects and faces in ventral temporal cortex. J. Cogn. Neurosci. 17, 580-590.

Olman, C.A., Ugurbil, K., Schrater, P., Kersten, D., 2004. BOLD fMRI and psychophysical measurements of contrast response to broadband images. Vis. Res. 44 669-683.

Olshausen, B.A., Field, D.J., 1996. Natural image statistics and efficient coding. Network 7, 333-339.

Olshausen, B.A., Field, D.J., 2004. Sparse coding of sensory inputs. Curr. Opin. Neurobiol. 14, 481-487.

Olshausen, B.A., Field, D.J., 2005. How close are we to understanding v1? Neural Comput. 17, 1665-1699.

Op De Beeck, H., Vogels, R., 2000. Spatial sensitivity of macaque inferior temporal neurons. J. Comp. Neurol. 426, 505-518.

Op de Beeck, H.P., Haushofer, J., Kanwisher, N.G., 2008. Interpreting fMRI data: maps, modules and dimensions. Nat. Rev. Neurosci. 9, 123-135.

Pachai, M.V., Sekuler, A.B., Bennett, P.J., 2013. Sensitivity to Information Conveyed by Horizontal Contours is Correlated with Face Identification Accuracy. Front. Psychol. 4, 74.

Peyrin, C., Baciu, M., Segebarth, C., Marendaz, C., 2004. Cerebral regions and hemispheric specialization for processing spatial frequencies during natural scene recognition. An event-related fMRI study. Neuroimage 23, 698-707.

Portilla, J., Simoncelli, E.P., 2000. A Parametric Texture Model based on Joint Statistics of Complex Wavelet Coefficients. Int. J. Comput. Vis. 40, 49-71.

Rajimehr, R., Devaney, K.J., Bilenko, N.Y., Young, J.C., Tootell, R.B., 2011. The "parahippocampal place area" responds preferentially to high spatial frequencies in humans and monkeys. PLoS Biol. 9, e1000608.

Rhodes, G., Brake, S., Atkinson, A.P., 1993. What's lost in inverted faces? Cognition 47, 25-57.

Rice, G.E., Watson, D.M., Hartley, T., Andrews, T.J., 2014. Low-level image properties of visual objects predict patterns of neural response across category-selective regions of the ventral visual pathway. J. Neurosci.: Off. J. Soc. Neurosci. 34, 8837-8844.

Rieger, J.W., Gegenfurtner, K.R., Schalk, F., Koechy, N., Heinze, H.J., Grueschow, M., 2013. BOLD responses in human V1 to local structure in natural scenes: Implications for theories of visual coding. J. Vis. 13, 19.
Riesenhuber, M., Poggio, T., 1999. Hierarchical models of object recognition in cortex. Nat. Neurosci. 2, 1019-1025.

Ringach, D.L., Shapley, R.M., Hawken, M.J., 2002. Orientation selectivity in macaque V1: diversity and laminar dependence. J. Neurosci.: Off. J. Soc. Neurosci. 22, 5639-5651.

Rossion, B., 2008. Picture-plane inversion leads to qualitative changes of face perception. Acta Psychol. 128, 274-289.

Rossion, B., Caldara, R., Seghier, M., Schuller, A.M., Lazeyras, F., Mayer, E., 2003. A network of occipito-temporal face-sensitive areas besides the right middle fusiform gyrus is necessary for normal face processing. Brain 126, 2381-2395.

Rossion, B., Hanseeuw, B., Dricot, L., 2012a. Defining face perception areas in the human brain: a large-scale factorial fMRI face localizer analysis. Brain Cogn. 79, $138-157$.

Rossion, B., Hanseeuw, B., Dricot, L., 2012b. Defining face perception areas in the human brain: A large-scale factorial fMRI face localizer analysis. Brain Cogn. 79, $138-157$.

Rust, N.C., Dicarlo, J.J., 2010. Selectivity and tolerance ("invariance") both increase as visual information propagates from cortical area V4 to IT. J. Neurosci.: Off. J. Soc. Neurosci. 30, 12978-12995.

Schiltz, C., Rossion, B., 2006. Faces are represented holistically in the human occipito-temporal cortex. Neuroimage 32, 1385-1394.

Schwarzlose, R.F., Baker, C.I., Kanwisher, N., 2005. Separate face and body selectivity on the fusiform gyrus. J. Neurosci.: Off. J. Soc. Neurosci. 25, 11055-11059.

Sclar, G., Freeman, R.D., 1982. Orientation selectivity in the cat's striate cortex is invariant with stimulus contrast. Exp. Brain Res. 46, 457-461.

Sereno, M.I., Dale, A.M., Reppas, J.B., Kwong, K.K., Belliveau, J.W., Brady, T.J., Rosen, B.R., Tootell, R.B., 1995. Borders of multiple visual areas in humans revealed by functional magnetic resonance imaging. Science 268, 889-893.

Sereno, M.I., McDonald, C.T., Allman, J.M., 1994. Analysis of retinotopic maps in extrastriate cortex. Cereb. Cortex 4, 601-620.

Sergent, J., Ohta, S., MacDonald, B., 1992. Functional neuroanatomy of face and object processing. A positron emission tomography study. Brain: J. Neurol. 115 (Pt 1), 15-36.

Serre, T., Oliva, A., Poggio, T., 2007. A feedforward architecture accounts for rapid categorization. Proc. Natl. Acad. Sci. USA 104, 6424-6429.

Skottun, B.C., Bradley, A., Sclar, G., Ohzawa, I., Freeman, R.D., 1987. The effects of contrast on visual orientation and spatial frequency discrimination: a comparison of single cells and behavior. J. Neurophysiol. 57, 773-786.

Smith, A.T., Kosillo, P., Williams, A.L., 2011. The confounding effect of response amplitude on MVPA performance measures. Neuroimage 56, 525-530.

Stojanoski, B., Cusack, R., 2014. Time to wave good-bye to phase scrambling: creating controlled scrambled images using diffeomorphic transformations. J. Vis. $14,1-16$.

Swisher, J.D., Gatenby, J.C., Gore, J.C., Wolfe, B.A., Moon, C.H., Kim, S.G., Tong, F., 2010. Multiscale pattern analysis of orientation-selective activity in the primary visual cortex. J. Neurosci. 30, 325-330.

Talairach, G., Tournoux, P., 1988. Co-planar Stereotaxic Atlas of the Human Brain. Thieme, New York.

Tjan, B.S., Lestou, V., Kourtzi, Z., 2006. Uncertainty and invariance in the human visual cortex. J. Neurophysiol. 96, 1556-1568.

van de Ven, V., Jacobs, C., Sack, A.T., 2012. Topographic contribution of early visual cortex to short-term memory consolidation: a transcranial magnetic stimulation study. J. Neurosci.: Off. J. Soc. Neurosci. 32, 4-11.

van der Schaaf, A., van Hateren, J.H., 1996. Modelling the power spectra of natural images: statistics and information. Vis. Res. 36, 2759-2770.

Vogels, R., Orban, G.A., 1990. How well do response changes of striate neurons signal differences in orientation: a study in the discriminating monkey. J. Neurosci.: Off. J. Soc. Neurosci. 10, 3543-3558.

Williams, N.R., Willenbockel, V., Gauthier, I., 2009. Sensitivity to spatial frequency and orientation content is not specific to face perception. Vis. Res. 49, 2353-2362.

Yacoub, E., Harel, N., Ugurbil, K., 2008. High-field fMRI unveils orientation columns in humans. Proc. Natl. Acad. Sci. USA 105, 10607-10612.

Yin, R.K., 1969. Looking at upside-down faces. J. Exp. Psychol. 81, 141-145.

Yovel, G., Kanwisher, N., 2004. Face perception: domain specific, not process specific. Neuron 44, 889-898.

Yovel, G., Kanwisher, N., 2005. The neural basis of the behavioral face-inversion effect. Curr. Biol. 15, 2256-2262. 